\title{
STUDYING THE EFFECT OF FINISHING WORK ON THE GEOMETRIC ACCURACY OF THE LASER CUT ELEMENTS
}

\author{
Agnieszka Skoczylas ${ }^{1}$ \\ ${ }^{1}$ Lublin University of Technology, Faculty of Mechanical Engineering, Department of Production Engineering, \\ Nadbystrzycka 36, 20-618 Lublin, Poland, e-mail: a.skoczylas@pollub.pl
}

Received: 2017.10.24

Accepted: 2018.02.01

Published: 2018.03.01

\begin{abstract}
The article presents the results of geometric accuracy studies of the $\mathrm{C} 45$ steel elements after laser cutting, and then subjected to finishing work. Burnishing and a combined machining and burnishing were applied as finishing works. Geometric accuracy studies of the elements after laser cutting and after finishing work were conducted in accordance with the PN - EN ISO 9013: 2017 - 04 standard. It has been noted that the finishing machining enables the improvement of geometric accuracy of the surface after laser cutting. Machining of elements after laser cutting allows for a reduction of the inclination index of the surface up to $42 \%$ with respect to the index value after laser cutting. Finishing milling makes it possible to reduce the surface inclination index more than twice. By performing burnishing of elements after laser cutting and finishing milling, no significant improvement of the element accuracy is obtained.
\end{abstract}

Keywords: laser cutting, geometric accuracy, finishing work

\section{INTRODUCTION}

The process of manufacturing machine components consists of a series of successive technological operations. Cutting is one of the first operations, from which the technological process of manufacturing the given element is usually started. The division of material can be done by mechanical means, e.g., cutting with scissors or presses, or with thermal methods, which should include plasma cutting, water-abrasive jet cutting, or with oxygen and laser [5].

Laser cutting is a material division technology, which has been successfully used since the 70 s of the XX century. The advantages of this cutting method includes the lack of direct impact through crushed material, on the material cut, with a narrow cutting gap with a minimal deviation and even cutting area, ease of automation and robotic cutting process and a broad range of applications. The weaknesses and limitations of the laser cutting technology include: maximal thickness of materials cut limited to $20-25 \mathrm{~mm}$, structural changes in the material, resulting in changes in the mechanical properties of structural elements and special requirements regarding the surface condition, chemical condition and physical properties of the materials cut $[13,14]$.

The course of the laser cutting process and the quality of the final product directly depend on the process parameters, such as: radiation modes, beam parameter product, type of cutting gas, diameter of the gas supplying nozzle, beam diameter in the focus, focus location and cutting speed. The quality and accuracy of the cut parts also affects the stability of the machine tool, as well as the properties of the material cut, in particular the absorption and thermal conductivity $[4-6,10]$.

Quality assessment of the edges and the surface after laser cutting is expressed by the following characteristic values based on the PN-EN ISO 9013: 2017 - 04 standard: rectangular tolerance or inclination of the cutting surface $-\mathrm{u}$, average height of the cutting surface profile - Rz5, reduc- 
tion of the thickness of the element cut $-\Delta \mathrm{a}$, cutting deviations $-\mathrm{n}$, melting the top edge $-\mathrm{r}$ and the occurrence of slag and solid droplets on the lower cutting edge [18].

According to PN-EN ISO 9013: 2017 - 04, the quality of components after thermal cutting can be attributed to the quality class. The division into appropriate groups is based on the characteristic values $u$ and Rz5. The quality of components after laser cutting is divided into 5 classes, where class 1 corresponds to the highest cutting quality, while class 5 is the lowest quality [18]. Referring to the guidelines in this standard [18] it is proposed that the quality class 1 was required for cutting without further mechanical machining, class 2 - when edges are prepared for arc welding.

Providing a large amount of heat to the object during laser cutting and deviation of the beam from the intended cutting path leads to the formation of the deviation of the contour cutting the element from a particular shape or position of the cutting line.

The are a lot of works in the literature, which concern the problem of the non-perpendicularity of the component surface after laser cutting to the surface of the plate cut.

The authors of the paper [7] have noted that while cutting a $18 \mathrm{~mm}$ plate made of S355J2 steel, there is a slight bulge on the cut surface. This is probably caused by the weakening of the laser beam, which, in turn, is somewhat distracted at the lower cutting edge, causing a groove.

During the laser cutting of a $10 \mathrm{~mm}$ plate made of stainless steel EN 1.4301, the laser beam, dipping into the material, undergoes deviation from the perpendicularity [1]. Depending on the cutting conditions, the deviation is between $0,3 \mathrm{~mm}$ and $0,75 \mathrm{~mm}$. Such a deviation causes an increase in the surplus value for subsequent technological operations and indicates the need to conduct the finishing treatment [1]. A similar phenomenon, lack of perpendicularity of the cutting contour, also occurs when $10 \mathrm{~mm}$ non-alloy steel plates are cut after the thermo-mechanical processing (S700MC) and heat-treated (S690QL) [3]. The value of the surface inclination index after thermal cutting $u$ is approximately $0,11 \mathrm{~mm}$ and $0,12 \mathrm{~mm}$ [3], which allows to qualify the surface to the first class according to PN - EN ISO 9013: $2017-04$.

The presence of the undesirable phenomenon, which is the deviation of the contour of the required cutting outline, constitutes prerequisites for performing the finishing treatment after laser cutting. Elimination of the contour cutting error is often done by milling and grinding, which is mainly dedicated for objects with bigger dimensions and more complex shapes [1], or by controlling the cutting parameters, or introducing appropriate corrections into programs dedicate to laser cutters.

The application of the above solutions does not always allow the achievement of the intended effects, so it is a good idea to undertake research in selecting the right machining process, which will allow for a complete or partial elimination of the contour cutting error with the simultaneous improvement of the stereo-metric and physical properties of the surface layer.

The burnishing, as a finishing machining of machine components [11], allows to reduce the surface roughness [8] and to increase the material share [16]. It is also possible to shape lubricating micro-plates on the burnished surfaces, which will increase the abrasion resistance of these surfaces $[2,12]$. During burnishing, the change in the concentration of defects of the crystalline structure often takes place, resulting in compressive stresses in the surface layer [17]. The consequence of changes in the proprieties of the surface layer due to burnishing is the increased abrasion and fatigue resistance [15]. Brushing, which is a variant of dynamic burnishing, is successfully used not only to improve the properties of the surface layer, but also to round the edges of the workpiece [9].

Considering the positive effects of burnishing, it was considered reasonable to undertake research on the use of this machining to improve the geometrical accuracy of the laser cut parts. As a result of burnishing, which is an inoperable treatment method, dimensional changes are caused by the following factors: plastic deformations and reduction of surface unevenness, as well as densification and crumbling of the structure [11].

The aim of the study was to evaluate the geometric accuracy of the surface of laser cut components, and then subjected to finishing machining, that is burnishing, as well as the combines milling and burnishing.

\section{METHODOLOGY OF RESEARCH}

Samples from non-alloy C45 steel were the object of the study (marked according to PN $-\mathrm{EN}$ $10083-1: 2008$ ). The rectangular $5 \times 8 \times 100 \mathrm{~mm}$ samples were made using the laser cutter LASER 
Amada 3000W of the Amada America Inc. company, using standard cutting parameters (cutting speed $v=1150 \mathrm{~mm} / \mathrm{min}$, power $\mathrm{P}=2,15 \mathrm{~kW}$, frequency $\mathrm{f}_{\mathrm{Hz}}=1280 \mathrm{~Hz}$, gas pressure $0,06 \mathrm{MPa}$, focus location $+13 \mathrm{~mm}$ and oxygen as working gas). Five ways of surface finishing machining have been identified after laser cutting:

- finishing milling,

- centrifugal burnishing,

- inishing milling and centrifugal burnishing,

- burnishing,

- finishing milling and burnishing.

The finishing milling and centrifugal burnishing process were carried out on the vertical machining centre FV - 580a. Perimeter milling was done using double-bit flycutter of the Sandvick company with a diameter of $20 \mathrm{~mm}$ with 215880 APKT10 bitts, covered with the TiN coating. The following parameters were used for concurrent milling: cutting depth $a_{p}=0,12 \mathrm{~mm}$, feed per tooth $f_{z}=0,067 \mathrm{~mm} /$ tooth, cutting speed $v_{c}=102 \mathrm{~m} / \mathrm{min}$.

During the centrifugal machining, a special burnishing head was the tool used for the treatment, with a diameter of $70 \mathrm{~mm}$, which has symmetrically distributed burnishing beads with a diameter of $d_{k}=6,3 \mathrm{~mm}$, in the amount of $z_{k}=$ 12. The following technological parameters were used during machining: tangential velocity of the burnishing head $v_{g}=1143 \mathrm{~m} / \mathrm{min}$, feed rate $v_{f}=3648 \mathrm{~mm} / \mathrm{min}$, cross traverse $f_{p}=0,08 \mathrm{~mm}$ and traverse $\mathrm{g}=0,5 \mathrm{~mm}$. The treatment was carried out in the presence of cooling-lubricating Mobile Cut liquid.

Burnishing was performed on a universal lathe C11/MB. A burnisher was used as a tool, consisting of a pressurizing unit and a burnishing element, which was a ball made of silicon nitride $\left(\mathrm{Si}_{3} \mathrm{~N}_{4}\right)$ with a diameter of $\mathrm{d}_{\mathrm{N}}=8 \mathrm{~mm}$. During burnishing, the burnishing power $\mathrm{F}=720 \mathrm{~N}$ was used, feed rate $\mathrm{f}=0,05 \mathrm{~mm} / \mathrm{r}$ and synthetic oil Mobile Vactra Oil.

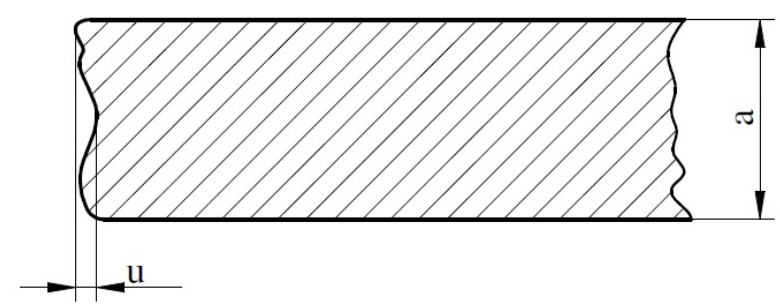

Fig. 1. The way of the determining $u$ index ( $\mathrm{u}-$ index, a - thickness of the samples)
The assessment of the dimensional-shape accuracy of laser cut components was performed after the finishing machining, in accordance with PN - EN ISO 9013: 2017 - 04. The $u$ index was used as a characteristic value describing the component quality, determined as the tolerance of perpendicularity or the inclination of the cutting surface. According to [18], the $\mathrm{u}$ index is the distance between two parallel straight lines, between which the profile of the cutting surface is located (fig. 1).

The measurements of the surface inclination index were made using the optical method, based on the surface image analysis after laser cutting, as well as after laser cutting and finishing machining. The 3D digital microscope of the VHX series -500 of the Keyence company was used for measurements, equipped with a digital camera with the ability to enlarge the analysed image from 100 to 1000 times. Figure 2 shows the position used for the measurements. Five samples were tested, on which measurement ware taken five times.

Samples, which were tested, were mounted in a vise bottom surface, which was perpendicular to the laser beam during the cutting process. The digital camera was used for scanning the $2 \mathrm{~mm} x$ $8 \mathrm{~mm}$ surface at 300 times magnification. Then, with the image analysis software, the contour of the scanned surface and the cutting surface inclination index $\mathrm{u}$ were determined.

\section{RESEARCH RESULTS}

The deviation of the shape from the intended contour, expressed by the inclination of the cutting surface, for $\mathrm{C} 45$ steel samples after laser cutting is $u=0,184 \pm 0,019 \mathrm{~mm}$, and the surface inclination angle after laser cutting $1^{\circ} 24^{\prime} \pm 0,21^{\prime}$. According to PN - EN ISO 9013, the obtained shape deviation value is a prerequisite for conducting mechanical processing. Figure 3 shows the surface deviation from the intended laser cutting contour.

The lower edges of samples are rounded, where the solid material is collected, which contributes to the formation of the metal overhang. Micro-cracks are also visible on the cut surface (fig.4a and 4b). The cause of the formation of discontinuities and micro-cracks is the uneven and rapid cooling of liquid metal on the surface.

Machining with centrifugal burnishing or burnishing after laser cutting allows for a reduc- 


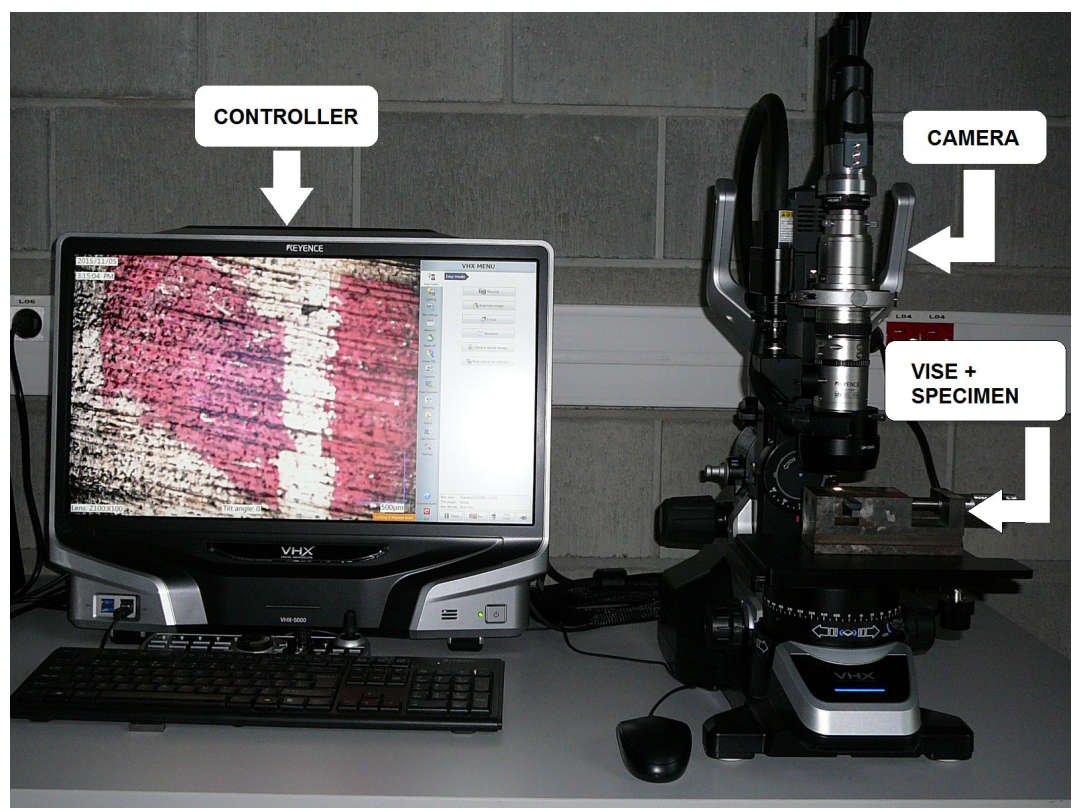

Fig. 2. View of the station to determine the inclination surface

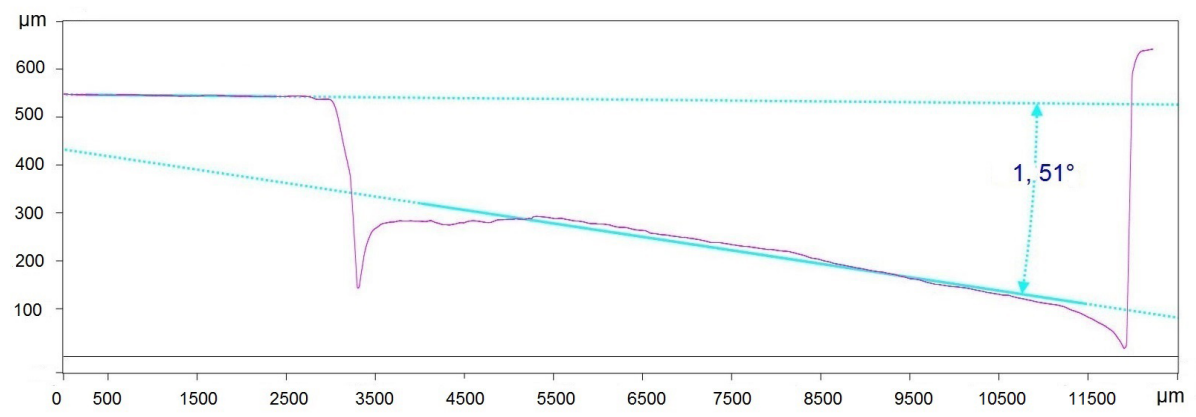

Fig. 3. Surface contour after laser cutting $\left(u=0,21 \mathrm{~mm}\right.$, bevel angle $\left.=1,51^{\circ}\right)$

a)

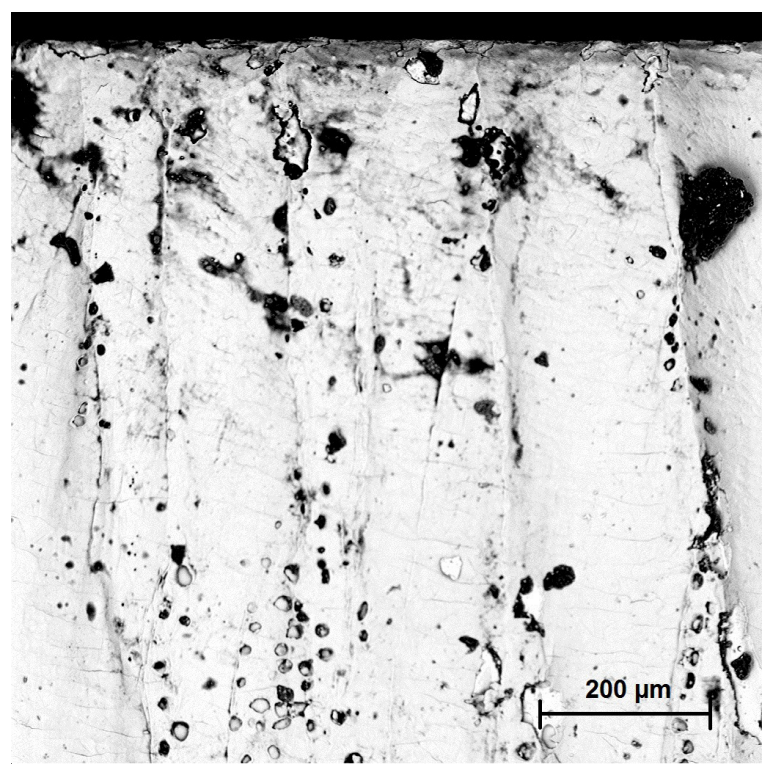

b)

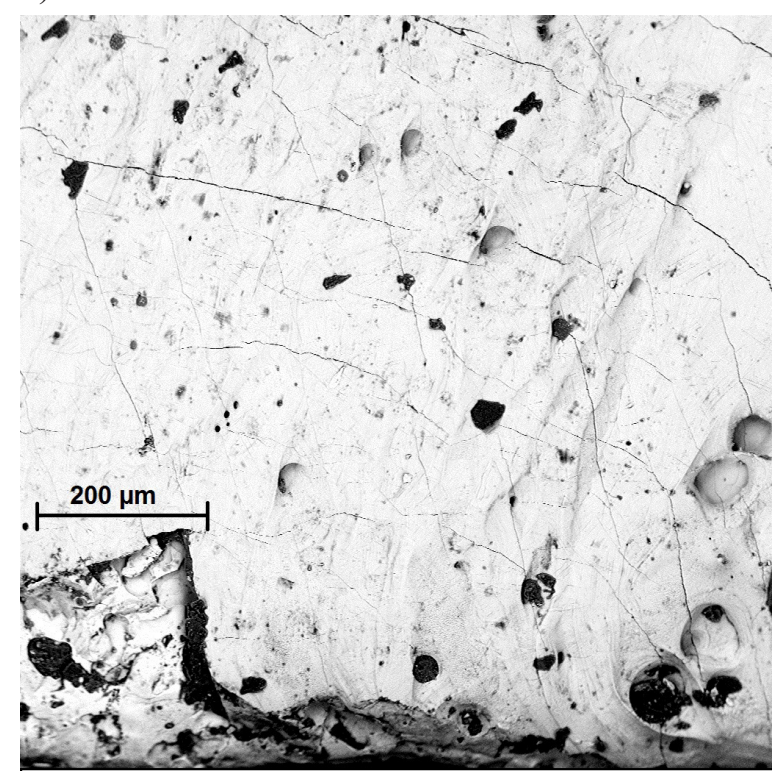

Fig. 4. View of the surface after laser cutting: a) in the laser beam input zone, b) in the laser beam output zone 
tion of the surface inclination $u$ (fig. 5). Burnishing causes the reduction of the shape deviation by approximately $39 \%$ with respect to values after laser cutting. This is probably due to the more intense deformation of the striated structure on the surface after laser cutting. In the case of centrifugal burnishing, the surface inclination decreased by $42 \%$ compared to the $u$ index after laser cut-

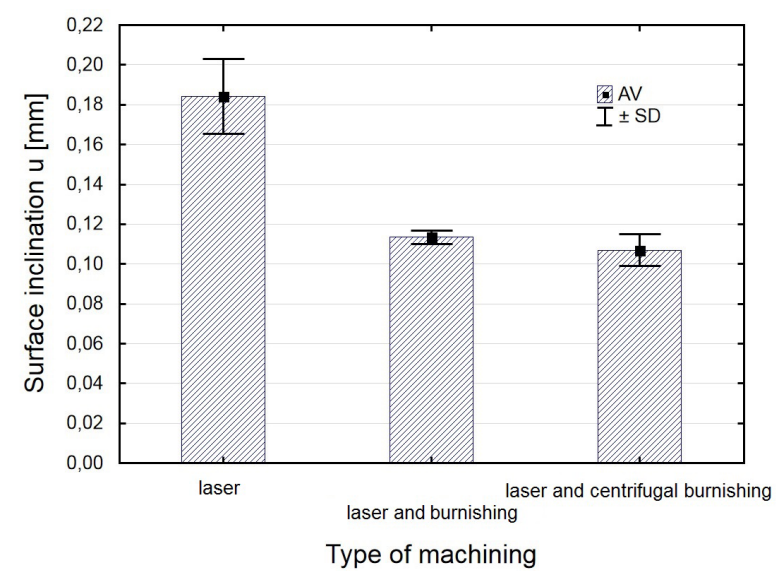

Fig. 5. Effect of machining type on surface inclination index $u$ ting. The impact energy coming from the burnishing head results in an increase in plastic deformations, which translates into a more even contour alignment. The surface contour after the finishing machining is more flattened, and the height difference between the maximum and minimum point of surface point is also partially reduced (fig. 6).

The machining allowed the reduction of the contour error. Cutting with a small cutting depth $\left(a_{p}=0,12 \mathrm{~mm}\right)$ made it possible to reduce the surface inclination index more than twice. The obtained value of the index $u=0,08 \pm 0,004 \mathrm{~mm}$ allows to classify the surface after laser cutting and finishing milling to the first quality class according to PN - EN ISO 9013: 2017 - 04 (fig. 7).

After a combined machining and burnishing, the improvement of the contour accuracy is $29 \%$, for burnishing, and approx. 13\% for centrifugal burnishing, with respect to the $\mathrm{u}$ index values after laser cutting and finishing milling (fig. 8). The combined machining and burnishing gives positive results in the improvement of the contour accuracy. The surface inclination index is smaller from $62 \%$ to $68 \%$ with respect to the u value after laser cutting.

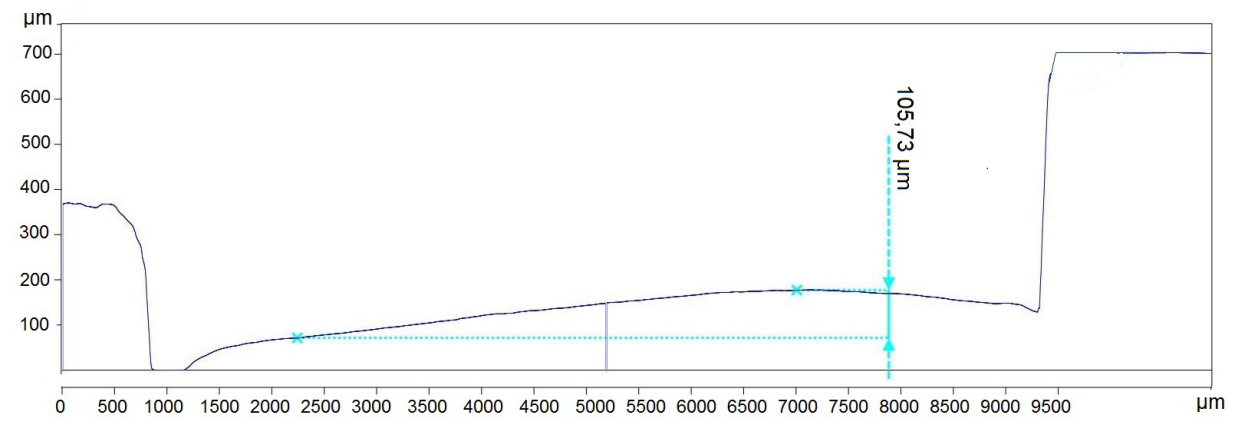

Fig. 6. Surface contour after laser cutting and centrifugal burnishing $\left(\mathrm{u}=0,105 \mathrm{~mm}\right.$, bevel angle $\left.=0,75^{\circ}\right)$

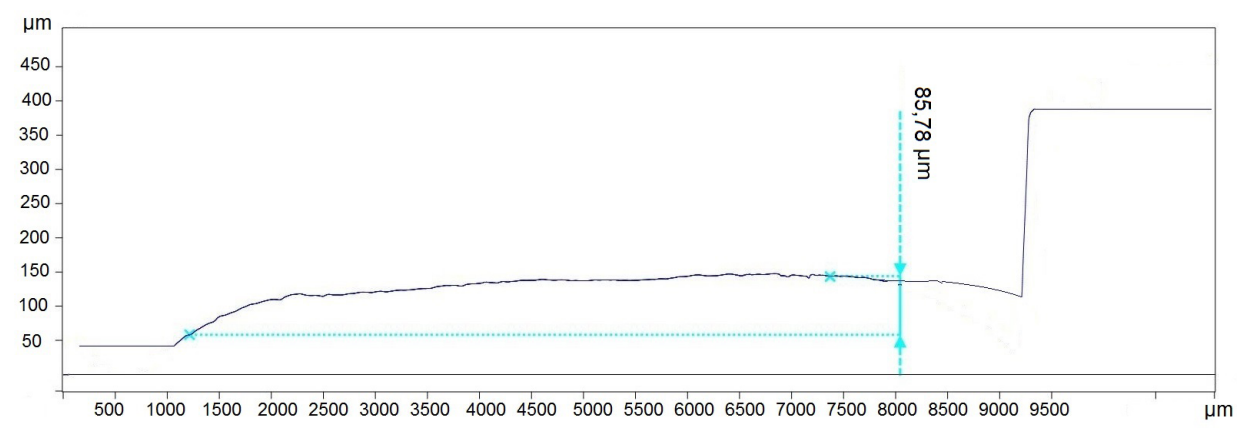

Fig. 7. Surface contour after laser cutting and finishing milling

$$
\left(\mathrm{u}=0,085 \mathrm{~mm} \text {, bevel angle }=0,61^{\circ}\right)
$$




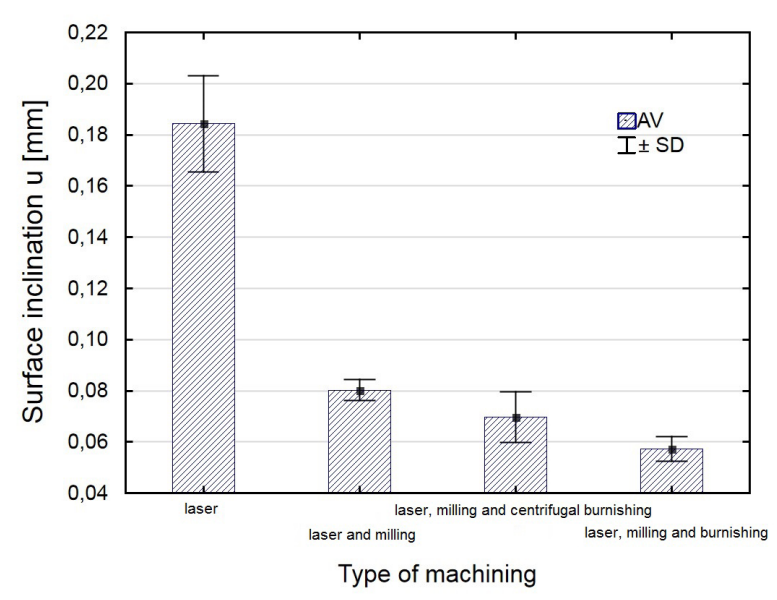

Fig. 8. Effect of machining type on surface inclination index $u$

\section{SUMMARY}

This paper analysed the impact of the component finishing machining on the component geometrical accuracy after laser cutting. The following conclusions summarize the results of the performed research:

- during laser cutting, as a result of the laser beam deviation from the intended path, the cutting surface deviation occurs from the intended contour, which constitutes prerequisites for performing mechanical machining,

- finishing milling allows to reduce the contour error almost twice, which enables the qualification of the surface to the first quality class according to PN - EN ISO 9013: 2017 - 04,

- the treatment of centrifugal burnishing or burnishing for components after laser cutting allows to reduce the surface inclination index from $39 \%$ to $42 \%$ with respect to the index value $u$ after laser cutting,

- by performing a combined machining and burnishing treatment, the value of $u$ index decreases from approx. 2,5 times to 3,2 times in relation to the surface inclination value after laser cutting.

\section{REFERENCES}

1. Feldshtein E., Koman I.: Wycinanie laserowe elementów o dużej grubości w blachach ze stali nierdzewnej. Przegląd Mechaniczny, 4, 2010, 13-18.

2. Galda L., Dzierwa A., Sep J., Pawlus P.: The effect of oil pockets shape and distribution on seizure resistance in lubricated sliding. Tribology Letters, 37, 2010, 301-311.
3. Górka J., Skiba R.: Wpływ procesów cięcia termicznego i strumieniem wody na właściwości i jakość powierzchni ciętych stali niskostopowych o wysokiej granicy plastyczności. Przegląd Spawalnictwa, 2, 2013, 11-18.

4. Jarosz K., Löschner P., Niesłony P.: Effect of cutting speed on surface quality and heat-affected zone in laser cutting of 316L stainless steel. Procedia Engineering, 149, 2016, 155-162.

5. Klimpel A.: Technologie laserowe. Wydawnictwo Politechniki Śląskiej, Gliwice, 2012.

6. Kołodzieczak P: Rodzaj cięcia laserowego. Przegląd Spawalnictwa, 7, 2015, 30-33.

7. Krawczyk R., Słania J., Cieśla D.: Porównanie metod cięcia termicznego stali. Przegląd Spawalnictwa, 7, 2015, 9-14.

8. Kułakowska A., Kukielka L., Kukielka K., Malag L., Patyk R., Bohdal L.: Possibility of steering of products surface layer properties in burnishing rolling process. Applied Mechanics and Materials, 474, 2014, 442-447.

9. Matuszak J., Zaleski K: Edge states after wire burnishing of magnesium alloys. Aircraft Engineering and Aerospace Technology, 86 (4), 2014, 328-335.

10. Orishich A.M., Shulyatyev V. B., Golyshev A A.: The utmost thickness of the cut sheet for the qualitative oxygen-assisted laser cutting of low-carbon steel. Physics Procedia, 83, 2016, 296-301.

11. Przybylski W.: Technologia obróbki nagniataniem. Wydawnictwo Naukowo- Techniczne, Warszawa, 1987.

12. Sep J., Pawlus P., Galda L: The effect of helical groove geometry on journal abrasive wear. Archives of Civil and Mechanical Engineering, 13, 2013, 150-157.

13. Yilbas B. S., Arif A. F. M., Abdul Aleem B. J: Laser cutting of rectangular blanks in thick sheet steel: Effect of cutting speed on thermal stresses. Journal of Materials Engineering and Performance, 19, 2010, 177-184.

14. Yilbas B. S., Shaukat, M. M., Ashraf F.: Laser cutting of various materials: Kerf width size analysis and life cycle assessment of cutting process. Optics \& Laser Technology, 93, 2017, 67-73.

15. Zaleski K.: The effect of vibratory and rotational shot peening and wear on fatigue life of steel. Eksploatacja i Niezawodność Maintenance and Reliability, 19 (1), 2017, 102-107.

16. Zaleski K., Skoczylas A.: Effect of vibration shot peening parameters upon shapes of bearing curves of alloy steel surface. Advances in Science and Technology Research Journal, 9 (25), 2015, 20-26.

17.Zaleski R., Zaleski K.: Positron annihilation in steel burnishing by vibratory shot peening. Acta Physica Polonica A, 110 (5), 2006, 739-746.

18. PN- EN ISO 9013:2017 - 04. Cięcie termiczne. Klasyfikacja ciecia termicznego. Specyfikacja geometrii wyrobu i tolerancje jakości. 